\title{
Diz çevresi periprostetik kırıkların tedavisi
}

\author{
Management of periprosthetic fractures around the knee
}

\author{
Hakan Kınık
}

Ankara Üniversitesi Tıp Fakültesi, Ortopedi ve Travmatoloji Anabilim Dalı, Ankara

\begin{abstract}
Diz çevresi periprostetik kırıklar, tüm periprostetik kırıklar arasında en fazla karşılaşılanıdır. Bunlar arasında da distal femur kırıkları birinci sırayı almaktadır. Maalesef bu kırıklardan sonra ilk yıl mortalitesi \%25'lere varan oranda yüksektir. Osteoporotik kırık tespiti zaten zor iken, önceden geçirdiği ameliyatlar nedeni ile yumuşak dokuları zarar görmüş, kemiği devaskülarize olmuş ve medüller kanalı başka implantlar ile dolu bir kemikte tespit çok daha zor ve tehlikelidir. Ortopedik cerraha düşen bu kırıkları yumuşak dokulara saygı göstererek en hızlı bir şekilde, iyi redükte edip hastayı bir an önce ayağa kaldırıp, üzerine basacak hale getirmektir. Bu derlemede bu kırıkların tedavisi ile ilgili özet bilgiler verilip çözüm yolları tartışılmaktadır.
\end{abstract}

Anahtar sözcükler: periprostetik; kırık; femur; tibia; patella; cerrahi tedavi; osteoporoz

\begin{abstract}
Periprosthetic fracture around the knee is the most common one among all periprosthetic fractures, and supracondylar fracture of the femur is the most common type around the knee. Unfortunately, the one-year mortality rate after a periprosthetic fracture is very high, reaching $25 \%$. While osteoporotic fracture fixation is already difficult, the management of these fractures remains a challenging problem because of associated osteoporosis, devascularization of the bone from the previous arthroplasty surgery, and medullary canal filling prosthesis. The treatment aim is rapid mobilization of the patient with a friendly soft tissue surgery, good reduction, and stable fixation. The objective of this article is to review the treatment principles of this type of fractures.
\end{abstract}

Key words: periprosthetic; fracture; femur; tibia; patella; surgical treatment, osteoporosis

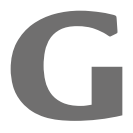

ünümüzde diz çevresi periprostetik kırıklar; yaşam süresinin uzaması, artroplasti ameliyatlarının artışı ve protezin uygulanması sırasındaki hatalar nedeni ile gittikçe artmaktadır. Tüm periprostetik kırıkların \%70'i diz çevresi kırıklardır ve erkeklerde daha fazla izlenir. Açık kırık ve çoklu kırık çok nadir olup, genellikle ev-içi düşmeler sonrası karşılaşılır. Total diz artroplastisi (TDA) sonrası en sık karşılaşılan kırık, $\% 0,6-2,5$ oranı ile suprakondiler femur kırığıdır. Tibia kırığı $\% 0,4$ oranında izlenirken, kırıkların $\% 0,1^{\prime} i$ ise intraoperatif olarak gerçekleşmektedir. ${ }^{[1]}$ Streubel ve ark.'na göre, bu kırıklardan sonra ilk 30 gün mortalitesi \%6, altı aylık mortalite \%18 ve maalesef ilk bir yıldaki mortalite $\% 25$ gibi ciddi bir rakamdır. ${ }^{[2]}$

Periprostetik kırıkların nedenleri ve çözüm yolları konusunda pek çok araştırmacı çalışmaktadır. Petersen ve ark.'na göre, TDA sonrası distal femurda özellikle ön yüzde stres kalkanlaması oluşarak ilk bir yılda kemik mineral dansitesi \%19-44 arası azalmakta ${ }^{[3]}$, bunun üzerine teknik hata olarak yapılan en ufak bir femur ön yüz çentiklenmesi, kırık riskini önemli derecede arttırmaktadır. Figgie ve ark.'na göre, anterior femoral çentiklenme yapılan hastalarda ilk sekiz yıl içinde kırık riski \%40 civarındadır. ${ }^{[4]}$ Çentiklenme yapılmış femurda normal femura göre bükülmede \%18, torsiyonda ise \%38 daha az güç ile kırık olabildiği bilinmektedir. Çentik büyüdükçe, derinleştikçe ve proteze yaklaştıkça bu risk artar.

TDA sonrası periprostetik kırık açısından risk faktörleri arasında; osteopeni (yaş, kortizon, RA...), stres noktaları (drill delikleri, lokal osteoliz, sert diz, tibial tüberkül osteotomisi...), nörolojik bozukluklar (yürüyüş bozuk, kasılmalar, fenitoin...), ileri varus deformitesi, posterior stabilize femoral komponentli tasarımlar (interkondiler bölgeden daha fazla kemik alırken intraoperatif kırık riski) ve daha çok tibial tarafta etkili olmak üzere komponentlerde gevşeme sayılabilir.

- Illetişim adresi: Prof. Dr. Hakan Kınık, Ankara Üniversitesi Tıp Fakültesi, Ek Bina K Blok 1. Kat, Samanpazarı, Ankara Tel: 0312 - 5082321 e-posta: hhkinik@gmail.com

- Geliş tarihi: 1 Eylül 2018 Kabul tarihi: 1 Ey/ül 2018 
Kırık riskini arttıran teknik hatalar ise; intramedüller kılavuzun kötü sokulması (ant penetrasyon), kötü kemik kesileri, komponentlerin çok güçlü çakılması, denemelerin eksentrik yerleştirilmesi, tibial tüberkül osteotomisi yapılması, posterior stabil protezler ve patellanın fazla rezeksiyonudur.

Bu kırıkların tedavisi ayrıca diğer kırıklara göre bazı ek zorluklar gösterir ve bazı faktörlerden negatif yönde etkilenebilir. Bunlar arasında; hastada osteoporoz/osteolizis varlığı, mevcut implantların tespiti bloke edebilmeleri, önceki ameliyatlara bağlı iskemi, deperiostizasyon ve çimentolama nedeni ile kırık iyileşmesinde gecikme, ve eşlik edebilen kemik defektlerinin varlığı (gevşek implant) sayılabilir.

Tedavi amaçlarımız, anatomik dizilimin sağlanması, yeterli kemik stoğunun korunması veya sağlanması, stabil bir protez oluşturulması, hastanın erken mobilizasyonu, kırığın kaynaması ve hastanın en az eski durumuna dönmesidir.

Tüm periprostetik kırıklarda tedavi stratejisi olarak:

- Protez stabil ise: tespit

- Protez instabil ise: tespit + revizyon

- Protez instabil + kemik kalitesi kötü ise:

- masif allogreft + kompozit protez veya

- mega-protez düşünülebilir.

\section{DISTAL FEMUR PERIPROSTETIK KIRIKLARI}

Hemen hepsi iyi fikse ve fonksiyonel diz protezi zemininde olur. Çoğu kırık femoral komponentin bittiği yerden gelişir. Stemli protezlerde daha üst seviyelerden kırık gelişebilir. Distal kemik stoğunun revizyona izin verip tespite izin vermemesi çok nadir olduğu ve çoğunda protez iyi fikse olduğu için, çoğu distal femur periprostetik kırığı kilitli plak ile tedavi edilebilir. Kim ve ark. ${ }^{[1]}$ tedaviye yardımcı olabilmek için bir sınıflama geliştirmişlerdir (Tablo 1). Buna göre; Tip 1A distal femur kırıklarında, kırık ya non-deplase ya da kolaylıkla tam olarak redükte olabilmektedir; kemik stoğu ve protez teknik olarak iyidir. Yazarlar, bu tip için konservatif tedaviyi önermektedir. Tip 1B'de protez ve kemik yapısı iyi olup redüksiyon sağlanamaz ve internal tespit önerilir. Tip 2 kırıklarda, kemik yapısı iyi olduğu halde ilk koyulan protez gevşemiş veya kötü dizilim ile konulduğu için uzun stemli bir protez ile revizyon gerektirir. Tip 3 kırıklar çok parçalı veya kemik yapısı kaynama veya revizyon protezini taşıyacak yapıya sahip olmadığı için, distal femoral replasman protezi ile tedavisi önerilmektedir.

Periprostetik distal femur kırıklarının konvansiyonel plaklar ile tedavisinde Davison ve ark. \%42 oranında varus kollaps ${ }^{[5]}$, Figgie ve ark. \%50 kötü sonuç[4] bildirmiştir. Güncel kilitli plaklara ulaşımda yetersizlik var ise, kamalı plak veya dinamik kondiler vida (DCS) gibi sabit açılı konvansiyonel plaklar, kablo serkilaj desteği ile uygulanabilir.

Günümüzde en sıklıkla kullanılan yöntem kilitli köprü plaklamadır. Bu yöntem ile tedavi sırasında önceden uzunluk, dizilim ve rotasyonun sağlanmasına dikkat edilmeli, hibrid plaklama yapılacak ise, önce konvansiyonel vidalar uygulanıp daha sonra kilitli vidalar kullanılmalı, kilitli vidaların bikortikal kullanımına ve mümkün olduğunca uzun plak seçimine dikkat edilmelidir (Şekil 1). Plak/vida doygunluğu hastanın osteoporoz derecesi, kırık şekli ve yüksekliğine göre ayarlanmalı, gerekirse minimal invaziv şekilde konulacak bir veya iki serkilaj kablosu uygulamasından çekinilmemelidir. Kırık proksimali kesinlikle sadece kablolar ile fikse edilmemelidir; muhakkak vida da kullanılmalı, kablolar mümkünse 'ataçman' aparatları üzerinden plağa tespit edilmelidir. Şaft kısmında konvansiyonel vida kullanılıyorsa, muhakkak kilitli vida da kullanılarak desteklenmelidir. Proksimalde kalça protezi varlığında, plak sistemi muhakkak kalça protezinin üzerini geçmelidir. Özellikle distal tespitte poli-aksiyel vidalar çok sayıda ve istenilen doğrultuda kilitli vida kullanımına olanak sağlayabilir. Çok distal veya parçalı kırıklarda mediyalden ikinci bir plak da tespite eklenebilir (Şekil 1). Kilitli plaklamada kaynamama oranı Ricci tarafından $\% 13$ olarak bildirilmiştir. ${ }^{[6]}$ Herrera ve ark., 415 hastalık bir seride kilitli plaklar ve retrograd çivilemeyi

Tablo 1. Distal femur ameliyat sonrası periprostetik kırıklarında Kim ve ark.'nın sınıflaması

\begin{tabular}{lllll}
\hline Tip & Kırık Redüksiyonu & Distal Kemik Stoğu & Komponent Pozisyon ve Tespiti & Tedavi \\
\hline $1 \mathrm{~A}$ & Evet & İyi & İyi & Konservatif \\
$1 \mathrm{~B}$ & Hayır & İyi & İyi & Tespit \\
2 & Evet/Hayır & İyi & Kötü & Uzun stem revizyon \\
3 & Evet/Hayır & Kötü & Kötü & Distal femoral replasman protezi
\end{tabular}



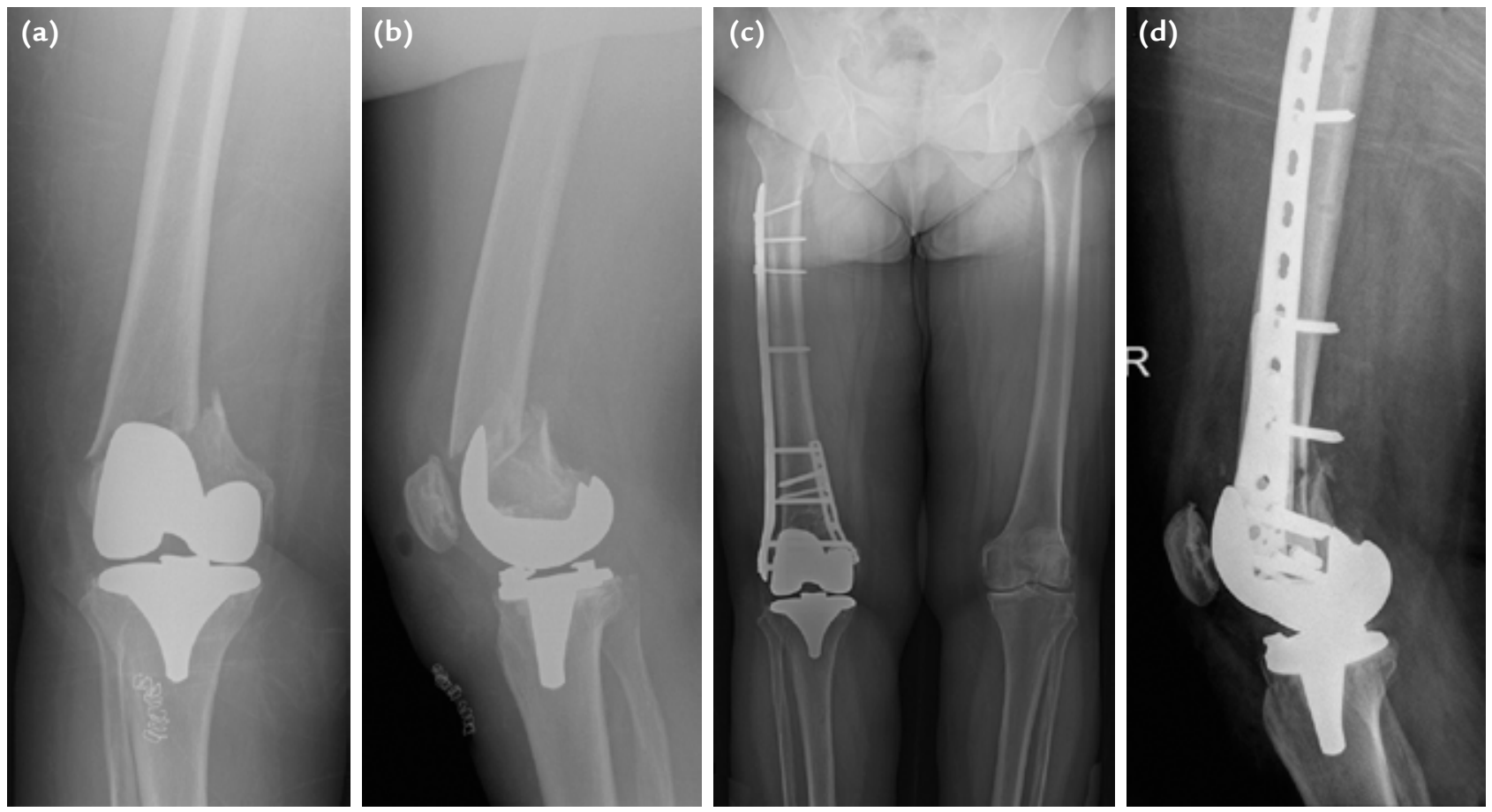

Şekil 1. a-d. Sağ distal femur kırığı ile baş vuran 61 yaşında kadın hastanın ön-arka ve yan grafileri. Grafilerden kırığın iki planda da oblik olduğu, parçalanma varlığı ve kemik stoğunun mediyal ve posteriorda daha iyi olduğu izlenmekte (a, b). Hastanın ekstremite diziliminin her iki planda da düzeltildiğine, çift kilitli plak kullanımına, lateraldeki plağın çok uzun olup tüm kemiği atellediğine, hibrid vidalama yapıldığına ve vida/plak yoğunluğuna dikkat ediniz (c, d).

karşılaştırmış; ortalama kaynamama oranını \%9, implant yetmezliği oranını \%4, enfeksiyon oranını ise \%3 olarak vermişlerdir. ${ }^{[7]}$

Distal femur periprostetik kırıklarının retrograd çivileme ile tedavisi, indirekt kırık redüksiyonu, minimal yumuşak doku hasarı, yükü kemik ile paylaşan bir santral implant varlığında daha güvenli yük vererek mobilizasyon gibi avantajlar taşırken; metafizer bölgede çivinin kemiğe temas etmemesi, eşlik edebilen kalça protezi varlığı, diz protezinin çivi geçişine izin vermeyecek tasarımda olması ve dizin en az $45-50^{\circ}$ fleksiyona gelebilme şartı nedeni ile bazen zor veya imkânsız olabilmektedir.

\section{PROKSIMAL TIBIAA PERIPROSTETIK KIRIKLARI}

Periprostetik tibia kırıkları, gelişen ve değişen tasarımlar ile günümüzde çok çok nadir görülmektedir. Felix ve ark.'nın ${ }^{[8]} 1997$ yılında yaptığı sınıflama bu kırıklar için hala kullanılmaktadır (Tablo 2). Yazarların serisinde en sık Tip I olarak sınıflandırdıkları tibia plato kırıkları bulunmaktadır. Yazarlar bu kırıkların varus dizilim bozukluğu sonucu oluşan stres kırıkları veya tibial komponentte gevşeme sonrası olduğuna inanmaktadır. Tip II kırıklar protez stemi çevresinde, Tip III kırıklar komponentin distalinden olur; Tip IV kırıklar ise tibial tüberosite kırıklarıdır.

Tablo 2. Proksimal tibia periprostetik kırıklarında Felix ve ark.'nın sınıflaması

\begin{tabular}{lllll}
\hline Sınıflama & Tip I & Tip II & Tip III & Tip IV \\
\hline KırıkYeri & Tibia plato & Stem çevresi & Protez distali & Tüberositas tibia \\
A & Protez iyi fikse & Protez iyi fikse & Protez iyi fikse & Protez iyi fikse \\
B & Protez gevşek & Protez gevşek & Protez gevşek & Protez gevşek \\
C & İntraoperatif & İntraoperatif & İntraoperatif & Intraoperatif
\end{tabular}



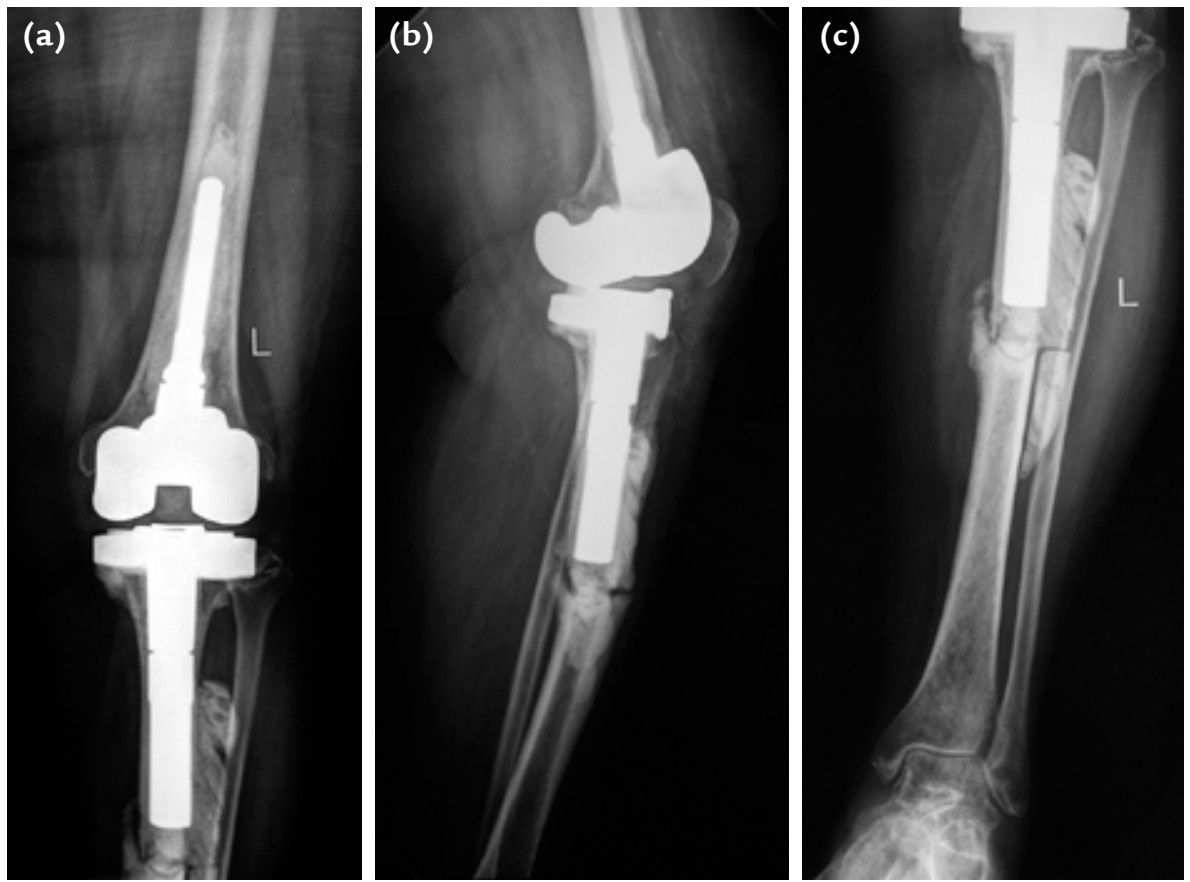

Şekil 2. a-e. Dış merkezde primer sonrası iki kere de revizyon diz protezi yapılan ve ağrı nedeni ile üzerine basmama ve stem tipinden kırık ile gelen 70 yaşında kadın hasta. Çimentolama sırasında oluşan kırık veya defektten tibia dışına çıkan çimento dikkat çekmekte. Tibiada varus ve prokur-vatum deformitesi mevcut $(\mathbf{a}-\mathbf{c})$. Lateralden yaklaşım ile kırık hattından dışarı çıkmış olan çimento temizlenmiş, aks iki planda düzeltilmiş, mümkün olan en uzun plak kullanılmış, proksimalde kanal içi dolu olduğu halde iki adet serkilaja ilaveten mümkün olan tüm deliklerden kilitli vidalar ile tespit yapılmış (d). Daha sonraki bir tarihte çekilen uzunluk grafisinde sistemdeki elastikiyet nedeni ile el değmemiş mediyal taraftan kallus atladığı izlenilmekte (e).
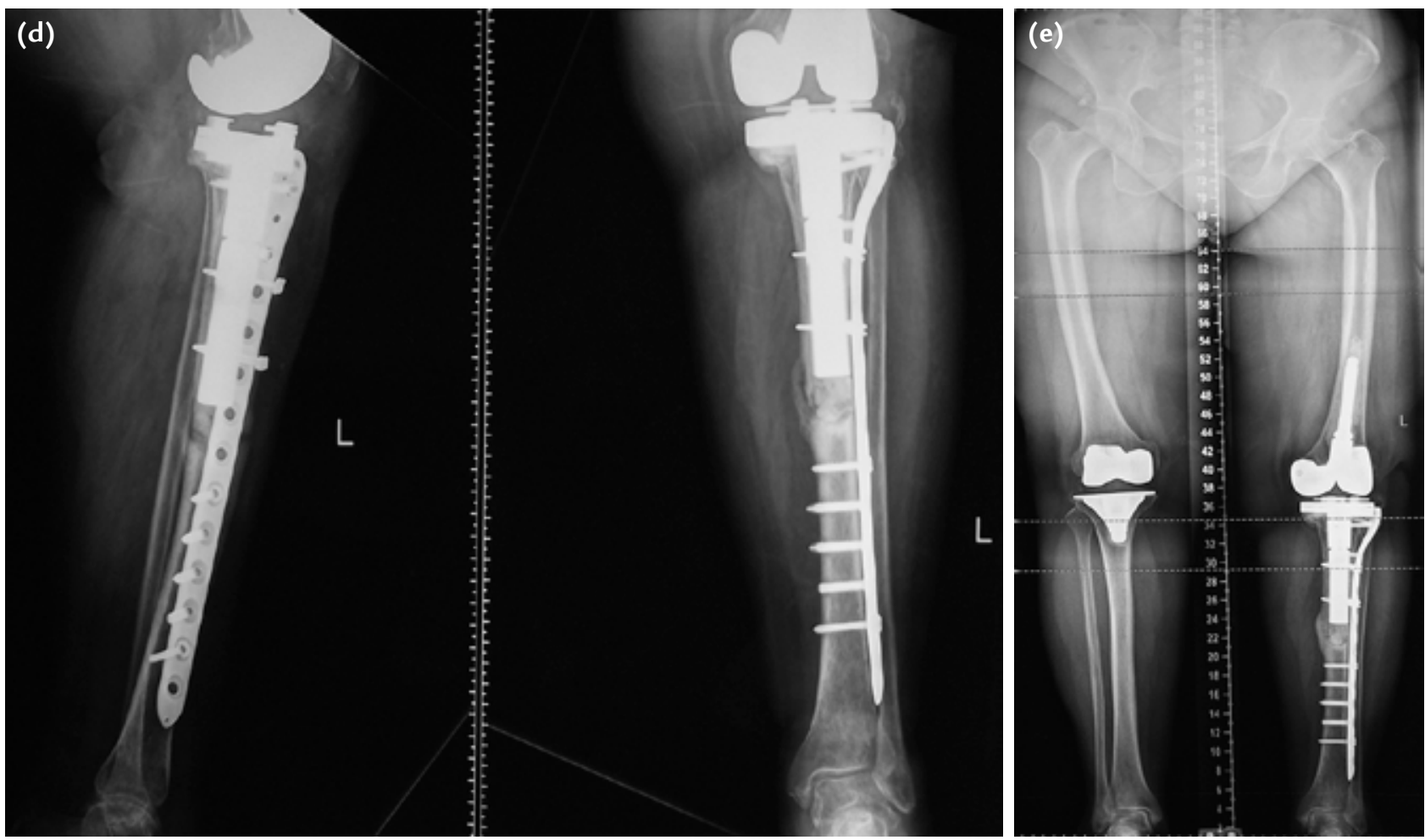

Varus dizilim bozukluğu veya gevşeme ile birlikte olan Tip I kırıklarda genellikle revizyon diz artroplastisi gerekir. Mediyaldeki varus yaratan defektin metal ogment veya kemik grefti ile güçlendirilmesi tavsiye edilir. Tip II ve III kırıklarda protezde gevşeme varsa uzun stemli protez ile revizyon, protez sağlam tutunuyor ise internal tespit önerilir. Çok nadir görünen Tip IV kırıklarda ise tespit ile birlikte kırığa yol açan osteolitik defektin greftlenmesi önerilmektedir. ${ }^{[8]}$ Tibia kırıklarının tespiti genellikle kilitli plaklar ile yapılmaktadır (Şekil 2). 
Tablo 3. Periprostetik patella kırıklarında Ortiguera ve Berry'nin sınıflaması

\begin{tabular}{lllll}
\hline Sınıflama & Tip I & Tip II & Tip IIla & Tip IIIb \\
\hline Ekstansör mekanizma & İntakt & Bozuk & İntakt & Intakt \\
Komponentin tespiti & İyi fikse & lyi fikse veya gevşek & Gevşek & Gevşek \\
Kemik stoğu & - & - & İyi & Kötü
\end{tabular}

\section{PERIPROSTETIK PATELLA KIRIKLARI}

Patella kırıkları, diz çevresi periprostetik kırıklar arasında distal femur sonrası ikinci sıklıkta görülür. Mayo kliniğin serisinde primer olgulardan sonra $\% 0,7$, revizyon olgulardan sonra ise $\% 1,8$ oranında görülmektedir. ${ }^{[9]}$ Suçlanan nedenler arasında; kemiğ $i n$ gereğinden fazla veya az kesilmesi, geniş lateral retinaküler gevşetme sonrası kan dolaşımının bozulması, patellofemoral uyumsuzluk, romatoid artrit, kortizon kullanımı ve direkt travmalar bulunur. ${ }^{[10]}$ Tedavide ekstansör mekanizmanın fonksiyonel olup olmaması, patellar komponentin gevşek olup olmaması ve mevcut kemik stok yeterliliği önemli olduğu için, günümüzde bu faktörleri ele alan Ortiguera ve Berry sınıflaması kullanılmakta$\operatorname{dir}$ (Tablo 3). ${ }^{[11]}$

Periprostetik patella kırıklarında cerrahi tedavi genellikle, ekstansör mekanizma bozuk ise, komponentte gevşeme var ise ve patellofemoral uyum/hareket bozukluğu var ise yapılır. Kırık sonrası ekstansör mekanizma hala bozulmamış ise konservatif tedavi ile kırığın iyileşmesi beklenebilir. Ekstansör mekanizmanın bozulduğu fakat protez tutunumunun sağlam kaldığı kırıklarda direkt internal tespit yapılırken; gevşek komponent varlığında tespit sonrası en az 10 mm'lik kemik stok var ise revizyon yapılabilir. Diğer durumlarda parsiyel veya total patellektomi ile birlikte patellar rezeksiyon artroplastisi yapılabilir.

Sonuç olarak; diz çevresi periprostetik kırıklar en sıklıkla görülen protez sonrası kırıklar olup, yüksek mortaliteleri nedeni ile çok dikkatli ve iyi planlanarak tek seferde tedavi edilmesi gereken kırıklardandır. Osteoporoz ile birlikte olduklarından bu kırıkların tespiti, deneyim kazanmış kişilerce yapılmalıdır. Tedavide köprüleme / göreceli denge prensipleri kullanılarak, kilitli plaklar veya intramedüller çivilerden yararlanılmaI, dizilime dikkat edilmeli, gerekiyorsa düzeltilmelidir. Gevşemiş veya hasar görmüş komponentlerin revizyonu şarttır. Tespit sırasında önceden konulmuş implantlar muhakkak 'by-pass'lanmalıdır. Tespitte sadece kablolara güvenilmemelidir. Yumuşak dokulara saygılı cerrahi yapılmalıdır. Kötü redüksiyon ve uygunsuz tespit ilkeleri ile yapılacak cerrahilerden sonra enfeksiyon, kaynamama ve implant yetmezliği gelişme riskinin yüksek olduğu ve sonrasında hastanın kaybedilebileceği akıldan çıkarılmamalıdır.

\section{KAYNAKLAR}

1. Kim K-I, Egol KA, Hozack WJ, Parvizi J. Periprosthetic Fractures after Total Knee Arthroplasties. Clin Orthop Relat Res 2006;446:167-75. Crossref

2. Streubel PN, Ricci WM, Wong A, Gardner MJ. Mortality after distal femur fractures in elderly patients. Clin Orthop Relat Res 2011;469(4):1188-96. Crossref

3. Petersen MM, Lauritzen JB, Pedersen JG, Lund B. Decreased bone density of the distal femur after uncemented knee arthroplasty. A 1-year follow-up of 29 knees. Acta Orthop Scand 1996;67(4):339-44. Crossref

4. Figgie MP, Goldberg VM, Figgie HE 3rd, Sobel M. The results of treatment of supracondylar fracture above total knee arthroplasty. J Arthroplasty 1990;5(3):267-76. Crossref

5. Davison BL. Varus collapse of comminuted distal femur fractures after open reduction and internal fixation with a lateral condylar buttress plate. Am J Orthop (Belle Mead NJ) 2003;32(1):27-30.

6. Ricci WM, Loftus T, Cox C, Borrelli J. Locked plates combined with minimally invasive insertion technique for the treatment of periprosthetic supracondylar femur fractures above a total knee arthroplasty. J Orthop Trauma 2006;20(3):190-6. Crossref

7. Herrera DA, Kregor PJ, Cole PA, Levy BA, Jönsson A, Zlowodzki $M$. Treatment of acute distal femur fractures above a total knee arthroplasty: Systematic review of 415 cases (19812006). Acta Orthop 2008;79(1):22-7. Crossref

8. Felix NA, Stuart MJ, Hanssen AD. Periprosthetic fractures of the tibia associated total knee arthroplasty. Clin Orthop Relat Res 1997;345:113-24. Crossref

9. Berry DJ. Epidemiology: Hip and knee. Orthop Clin North Am 1999;30(2):183-90.

10. Ritter MA, Campbell ED. Postoperative patellar complications with or without lateral release during total knee arthroplasty. Clin Orthop Relat Res 1987;(219):163-8. Crossref

11. Ortiguera CJ, Berry DJ. Patellar fracture after total knee arthroplasty. J Bone Joint Surg Am 2002;84-A(4):532-40. Crossref 